\title{
Longevity Expectations and Death: Can People Predict Their Own Demise?
}

\author{
By V. Kerry Smith, Donald H. Taylor, Jr., And Frank A. Sloan*
}

Many economists are convinced that when individuals are asked to formulate probabilities they are unlikely to do it correctly (Mark J. Machina, 1990). However, the same analysts would likely add that people do have a reasonably articulated, but biased, internal scale for risk perceptions. As a result, the extent of bias in these subjective perceptions has been an important unresolved issue. For the most part, the available evidence on these issues stems from simple laboratory experiments and comparisons of subjective and expert risk assessments for a diverse array of activities (Baruch Fischhoff et al., 1993). Current public policy associated with many different sources of risk relies on consumer sovereignty and implicitly trusts that these biases in risk perception will not be great. Until recently there has been no opportunity to test this question outside the setting of laboratory experiments.

This study tests the reliability of the most important subjective risk assessment a person can make: an expectation about personal longevity. Using four waves of the Health and Retirement Survey (HRS) (Thomas F. Juster and Richard Suzman, 1995), we tested whether longevity expectations match actual mortality at the individual level. Three distinct conclusions emerged from the analysis. First, subjective beliefs about longevity are consistent with indi-

* Smith: Center for Environmental and Resource Economic Policy, and Resources for the Future, Campus Box 8109, North Carolina State University, Raleigh, NC 27695; Taylor: Center for Health Policy, Law and Management, Terry Sanford Institute of Public Policy, Duke University, 122 Old Chemistry Building, Box 90253, Duke University, Durham, NC 27708; Sloan: Center for Health Policy, Law and Management and Department of Economics, Duke University, 125 Old Chemistry Building, Box 90253, Duke University, Durham, NC 27708. Partial support for this research was provided by the Robert Wood Johnson Foundation and by National Institute on Aging Grant No. 1R01AG-15868. Thanks are due an anonymous referee and Matthew Shapiro for very helpful comments on earlier drafts of this paper. viduals' observed survival patterns. After accounting for the selected nature of the sample of surviving respondents for each wave of the HRS survey, we found that observed deaths are "signaled" through the lower longevity expectations respondents report in earlier interviews. Second, the evolution of subjective beliefs from those who later die displays a consistent decline over time. In contrast, survivors' longevity expectations, on average, are higher and approximately constant over the time span observed in the panel. Third, longevity expectations do respond negatively both to serious, new health shocks and to increases in individuals' functional limitations. Thus, an individual's longevity expectation is a fairly accurate index of personal survival probability, both in its responsiveness to events that experts would suggest increase the odds of death and as a prediction of future mortality. However, models based on this subjective probability do not reflect all of the private information people have about their survival prospects. A simple test rejects this hypothesis.

In the first section of this paper, we develop our hypotheses and relate them to the current literature. The second section describes the HRS survey, the third presents our findings, and the last comments on the implications of these findings for economic models.

\section{Background}

Most evaluations of longevity expectations have been confined to demographically matched comparisons of the means of these subjective probabilities with corresponding life tables. Daniel S. Hamermesh (1985) initiated this line of research. Using two different samples, he found that people do incorporate improvements in life expectancy into their beliefs about personal longevity and time horizons. However, when compared with actuarial distributions for the probability of surviving to a specific year, the 
subjective distributions were flatter and exhibited greater variance. Moreover, they also appeared to display disproportionate reliance on the longevity patterns of relatives.

The HRS panel structure provides a unique opportunity to examine the evolution of subjective longevity expectations over time. Two recent studies by Michael D. Hurd and Kathleen McGarry (1998) and Hurd et al. (1999), which use the HRS and the Asset and Health Dynamics among the Oldest-Old study (AHEAD) samples, are relevant to our analysis. Hurd and McGarry (1998) focused primarily on the predictive validity of subjective probabilities, considering how longevity expectations respond to new information and whether these expectations serve as predictions of mortality. Their analysis considered waves 1 and 2 of the HRS. ${ }^{1}$ They found that subjective beliefs decline upon the death of a parent and respond to only one type of new health outcome: cancer. Hurd et al. (1999) found that, for an older population (i.e., aged 70 or older), subjective beliefs do respond (in stronger terms than in the HRS sample) to the onset of health conditions. ${ }^{2}$

Our analysis introduces a new question to the evaluation of longevity expectations. It considers whether these responses can be relied upon to include all of the information people have to form their subjective survival probabilities. It also extends earlier analyses of the role of longevity expectations as predictors of mortality in three ways. First, two additional waves of interviews offer a more complete record to evaluate subjective beliefs. Second, our analysis recognizes the censoring over time that occurs in the sample of individuals who are available for testing the predictive value of longevity

\footnotetext{
${ }^{1}$ Our results reveal that expanding the time horizon for the panel helps to explain Hurd and McGarry's (1998) results. Their analysis of waves 1 and 2 of the HRS indicates a decline in subjective longevity between waves 1 and 2 for survivors, a response inconsistent with what we would expect with age. By extending the analysis to waves 3 and 4 , we find that for those surviving to wave 4 , subjective beliefs about longevity do increase between waves 2 and 3 .

${ }^{2}$ This comparison of subjective longevity with actual mortality is incomplete due to the low response rate to the longevity expectations question. Nonetheless, with subjective probability measured as a difference with respect to the life-table survival rate for the target age, Hurd et al. (1999) found this deviation to be a significant determinant of mortality.
}

expectations. To do so, we used the Wynand P. M. M. van de Ven and Bernard M. S. van Praag (1981) proposal, which extends James J. Heckman's (1979) selection model to the case of a probit with sample selection. Separate models were estimated for deaths between waves 3 and 4, taking into account deaths between waves 2 and 3, as well as for deaths between waves 1 and 2 . We also considered deaths between waves 2 and 3, allowing for earlier losses. By focusing on new health events and changes in activity restrictions, the estimated models distinguish separate effects, over time, for changes in health status and household income.

Finally, we exploited the unique advantages of the panel to evaluate longevity expectations over time. This was accomplished by considering specific subsamples (e.g., those individuals either dead or surviving at the time of a specific interview wave). For example, to develop insight into the temporal evolution of longevity expectations, we considered those individuals who died between waves 3 and 4 and examined the time profile of their earlier responses to the question about longevity expectations.

\section{Data}

Four waves of the HRS (waves 1-4) provided the basis for this study. The HRS is a national panel study of birth cohorts 1931-1941 and the spouses of the married members of the cohort (F. Thomas Juster and Richard Suzman, 1995). Respondents to wave 1 of the HRS, which was conducted in 1992, were 51-61 years old (with some spouses being younger or older than this). The baseline included 12,652 persons (7,600 households), with oversamples for Mexican-Americans, African-Americans, and residents of Florida. ${ }^{3}$ The objectives underlying the development of the panel were (1) to

\footnotetext{
${ }^{3}$ HRS oversampled residents of the state of Florida because the congressional appropriation language that funded HRS stated that special attention be paid to areas with a large number and high density of older persons. Florida was chosen over Arizona because of the relatively small number of elders in Arizona; it was chosen over California because of the lower density of elders in California. The Florida oversample was financed by a special appropriation from the National Institute on Aging general budget as well as from the State of Florida (Juster and Suzman, 1995).
} 
explain the antecedents and consequences of retirement; (2) to examine the relationships among health, income, and wealth over time, as well as life-cycle patterns of wealth accumulation and consumption; (3) to monitor work and disability interactions; and (4) to provide the baseline for a long-term epidemiological study on aging (Juster and Suzman, 1995). Baseline interviews were conducted in respondents' homes, with telephone follow-ups scheduled every two years for 12 years. HRS contains extensive information on health behaviors, health and functional status, and individuals' subjective perceptions of longevity. HRS is especially well suited to our objective because it includes a question that closely parallels the original Hamermesh (1985) formulation of longevity expectations.

During each wave of the survey, respondents were asked about their longevity expectations. ${ }^{4}$ We analyzed three groups from the HRS. The first sample consisted of all persons responding to wave $1(N=12,652)$; for this sample, we assessed mortality by wave 2 . The second sample consisted of individuals who responded to waves 1 and 2 of the HRS $(N=11,492)$; for this sample, we assessed mortality by wave 3 . We also assessed mortality by wave 4 for those persons who survived and responded to waves 1-3. Although a small number of respondents died between waves (see Table 1), the death rate was consistent with what would be expected from standard life-tables. ${ }^{5}$

\footnotetext{
${ }^{4}$ The specific question uses a Likert scale and asks, "With 0 representing absolutely no chance, and 100 absolute certainty, what is the chance that you will live to be 75 years of age or older?" In wave 2, the same question was asked but on a scale of 0 to 10 . In both cases our analysis normalizes the variable so that it falls in the $0-1.0$ range. This question was asked in waves 3 and 4 in exactly the same way it was asked in wave 2 , both in terms of wording and scale. Smith et al. (1987) found that changing the format of the Likert scales, which are used to elicit subjective measures of risk perceptions, did not affect statistical models describing the updating of risk in response to new information.

${ }^{5}$ Attrition complicates the process of judging the death rates in the HRS panel. To evaluate the consistency of the death rate in the HRS sample, we considered deaths between waves 3 and 4, estimating the deaths per thousand respondents by using the sample with sufficient information to estimate our mortality models. Deaths between waves 3 and 4 would imply a rate of 17.4 deaths per thousand. However, the HRS has experienced approximately 20-
}

\section{Findings}

Table 1 reports our test of the performance of subjective longevity in predicting mortality. Each model takes into account the censoring associated with death in preceding waves. After reporting the means for the variables in each model, based on the sample available for analysis of deaths between waves 3 and 4 in the first column, Table 1 provides two models for deaths between waves 3 and 4 . The first model considers the role of longevity expectations, new health conditions between waves 2 and 3 , changes in the count of each respondent's reported limitations in activities of daily living between waves 2 and 3, smoking status in the preceding wave, and family income in the preceding wave. The model also includes two selection effects: the first takes into account the fact that respondents must be alive (and participating) in wave 3 in order to be eligible to be counted as a death between waves 3 and 4 . This selection model includes the following as determinants of being alive for wave 3: the longevity expectation in wave 2 , smoking status in wave 2 , new health shocks between waves 1 and 2 , earlier changes in activity limitations (i.e., between waves 1 and 2), family income in wave 2 , and some demographic characteristics. The second selection effect is accounted for by using an independently estimated inverse Mills ratio for survival between waves 1 and 2 . This selection effect takes into account the sample censoring associated with respondents living to wave $2 .{ }^{6}$

Our results confirm the dramatic advantages

percent attrition that is not due to death. Adjusting the base sample size to include these former respondents who did not die by wave 4 , we have an adjusted death rate of 14.5 per thousand. The median age of these respondents when they entered the HRS in 1992 was 55 in wave 1 . By wave 4, this median would be 61 . A national measure of deaths per thousand individuals at age 61 (as of 1996) is 12.54; at age 62 it is 13.70 (U.S. Department of Commerce, 1999 Table 129). Thus, the death rate for the HRS corresponds fairly closely, given the small sample, to what would be expected for this age-group.

${ }^{6}$ Although one could estimate the two selection effects jointly with the final probit model for mortality, our adaptation to the Heckman (1979) two-step logic is a convenient and asymptotically equivalent way (Halbert White, 1982) to gauge the importance of the multiple selections. The results confirm that our basic conclusions are not changed whether or not we account for this earlier selection effect. 
Table 1-Probit with Sample Selection for Mortality in Waves 3 and $4^{\mathrm{a}}$

\begin{tabular}{|c|c|c|c|c|c|}
\hline Independent variables & $\begin{array}{c}\text { Means in wave } \\
j=4\end{array}$ & $\begin{array}{c}\text { Death in wave } \\
j=4\end{array}$ & $\begin{array}{c}\text { Death in wave } \\
j=4\end{array}$ & $\begin{array}{l}\text { Death in wave } \\
\quad j=3\end{array}$ & $\begin{array}{c}\text { Means in wave } \\
j=3\end{array}$ \\
\hline Live to 75, wave $j-1$ & $\begin{array}{c}0.653 \\
(0.303)\end{array}$ & $\begin{array}{c}-0.233 \dagger \\
(0.125)\end{array}$ & $\begin{array}{r}-0.307 \\
(0.122)\end{array}$ & $\begin{array}{c}-0.517 \\
(0.118)\end{array}$ & $\begin{array}{c}0.635 \\
(0.289)\end{array}$ \\
\hline Smoke, wave $j-1$ & $\begin{array}{c}0.232 \\
(0.422)\end{array}$ & $\begin{array}{l}0.355 \\
(0.076)\end{array}$ & & $\begin{array}{c}0.297 \\
(0.069)\end{array}$ & $\begin{array}{c}0.244 \\
(0.429)\end{array}$ \\
\hline Shock, wave $j-1$ & $\begin{array}{c}0.082 \\
(0.274)\end{array}$ & $\begin{array}{c}0.351 \\
(0.100)\end{array}$ & $\begin{array}{c}0.411 \\
(0.096)\end{array}$ & $\begin{array}{c}0.439 \\
(0.097)\end{array}$ & $\begin{array}{c}0.060 \\
(0.238)\end{array}$ \\
\hline $\begin{array}{l}\text { Change in count of } \\
\text { activity limitations, } \\
j-2 \text { to } j-1\end{array}$ & $\begin{array}{c}0.478 \\
(1.027)\end{array}$ & $\begin{array}{c}0.095 \\
(0.026)\end{array}$ & $\begin{array}{c}0.098 \\
(0.026)\end{array}$ & $\begin{array}{c}0.146 \\
(0.030)\end{array}$ & $\begin{array}{c}0.211 \\
(0.703)\end{array}$ \\
\hline $\begin{array}{l}\text { Income in wave } j-1 \\
\quad \text { (in } 10,000 \text { ) }\end{array}$ & $\begin{array}{c}4.278 \\
(5.808)\end{array}$ & $\begin{array}{c}-0.031 \\
(0.014)\end{array}$ & & $\begin{array}{c}-0.040 \\
(0.015)\end{array}$ & $\begin{array}{c}4.693 \\
(15.378)\end{array}$ \\
\hline Intercept & & $\begin{array}{c}-2.104 \\
(0.102)\end{array}$ & $\begin{array}{l}-2.054 \\
(0.087)\end{array}$ & $\begin{array}{r}-1.870 \\
(0.091)\end{array}$ & \\
\hline \multicolumn{6}{|l|}{$\begin{array}{l}\text { Selection Model (alive } \\
\text { in preceding wave) }\end{array}$} \\
\hline $\begin{array}{l}\text { Live to } 75 \text { in wave } \\
j-2\end{array}$ & $\begin{array}{c}0.639 \\
(0.286)\end{array}$ & $\begin{array}{c}0.365 \\
(0.025)\end{array}$ & $\begin{array}{c}0.348 \\
(0.025)\end{array}$ & $\begin{array}{c}0.670 \\
(0.024)\end{array}$ & $\begin{array}{c}0.647 \\
(0.294)\end{array}$ \\
\hline Smoke in wave $j-2$ & $\begin{array}{c}0.242 \\
(0.428)\end{array}$ & $\begin{array}{c}-0.182 \\
(0.016)\end{array}$ & & $\begin{array}{l}-0.210 \\
(0.016)\end{array}$ & $\begin{array}{c}0.271 \\
(0.445)\end{array}$ \\
\hline Shock in wave $j-2$ & $\begin{array}{c}0.053 \\
(0.224)\end{array}$ & $\begin{array}{c}-0.466 \\
(0.033)\end{array}$ & $\begin{array}{r}-0.504 \\
(0.032)\end{array}$ & & \\
\hline $\begin{array}{l}\text { Change in count of } \\
\text { stated activity } \\
\text { limitations, } j-3 \text { to } \\
j-2\end{array}$ & $\begin{array}{c}0.209 \\
(0.703)\end{array}$ & $\begin{array}{c}-0.151 \\
(0.011)\end{array}$ & $\begin{array}{c}-0.151 \\
(0.011)\end{array}$ & & \\
\hline Income in wave $j-2$ & $\begin{array}{c}4.844 \\
(16.590)\end{array}$ & $\begin{array}{c}0.026 \\
(0.002)\end{array}$ & & $\begin{array}{c}0.060 \\
(0.003)\end{array}$ & $\begin{array}{c}4.801 \\
(4.815)\end{array}$ \\
\hline Mills ratio ${ }^{\mathrm{b}}$ & & $\begin{array}{c}-6.230 \\
(0.382)\end{array}$ & $\begin{array}{c}7.854 \\
(0.363)\end{array}$ & & \\
\hline Age in wave 1 & $\begin{array}{l}54.470 \\
(4.751)\end{array}$ & & & $\begin{array}{l}-0.058 \\
(0.001)\end{array}$ & $\begin{array}{l}54.866 \\
(5.037)\end{array}$ \\
\hline Male $(=1)$ & $\begin{array}{c}0.393 \\
(0.488)\end{array}$ & & & $\begin{array}{c}-0.266 \\
(0.016)\end{array}$ & $\begin{array}{c}0.416 \\
(0.493)\end{array}$ \\
\hline African-American $(=1)$ & $\begin{array}{c}0.143 \\
(0.350)\end{array}$ & & & $\begin{array}{c}-0.304 \\
(0.019)\end{array}$ & $\begin{array}{c}0.150 \\
(0.357)\end{array}$ \\
\hline Married in wave $j-2$ & $\begin{array}{c}0.781 \\
(0.414)\end{array}$ & & & $\begin{array}{r}-0.059 \\
(0.019)\end{array}$ & $\begin{array}{c}0.806 \\
(0.396)\end{array}$ \\
\hline Intercept & & $\begin{array}{c}2.122 \\
(0.026)\end{array}$ & $\begin{array}{c}2.240 \\
(0.023)\end{array}$ & $\begin{array}{l}5.121 \\
(0.087)\end{array}$ & \\
\hline Rho & & $\begin{array}{c}0.612 \\
(0.151)^{\mathrm{c}}\end{array}$ & $\begin{array}{c}0.645 \\
(0.087)\end{array}$ & $\begin{array}{c}0.697 \\
(0.101)^{\mathrm{c}}\end{array}$ & \\
\hline Deaths in wave $j$ & $\begin{array}{c}0.017 \\
(0.131)\end{array}$ & & & & $\begin{array}{c}0.018 \\
(0.132)\end{array}$ \\
\hline \multicolumn{6}{|l|}{ Observations } \\
\hline $\begin{array}{l}\text { Total } \\
\text { Censored }\end{array}$ & & $\begin{array}{c}7,815 \\
167\end{array}$ & $\begin{array}{c}7,993 \\
168\end{array}$ & $\begin{array}{c}9,472 \\
153\end{array}$ & \\
\hline
\end{tabular}

a The numbers in parentheses for the probit models are asymptotic standard errors. All estimated coefficients, except those marked with $\dagger$, are significantly different from zero; $p$-values $=0.05$ or less. In the one case with a $\dagger, p=0.062$. The numbers in parentheses are the standard deviations.

b The probit model (with asymptotic standard errors in parentheses) used to estimate the inverse Mills ratio is alive $2=$ $3.767(0.419)+0.649(0.102)$ live to 75 , wave $1-0.034(0.007)$ age, wave $1-0.216(0.068)$ male $(=1)-0.003(0.089)$ married, wave $1(=1)-0.240(0.082)$ African-American $(=1)+0.053(0.017)$ income in wave $1-0.187(0.070)$ smoke in wave $1(=1)$.

${ }^{\mathrm{c}}$ Chi-square statistic for the Wald test of the null hypothesis rho $=0$; all models reject null hypothesis at $p$-value $=0.01$ or less. 
realized in using the panel structure of the HRS. All of the hypothesized determinants of mortality are statistically significant and consistent with a priori expectations. The time profile of longevity expectations is consistently linked to subsequent observed mortality. Longevity expectations have a positive and significant effect on survival to wave 3 in the selection model. In the mortality model, these expectations have a sign change consistent with later statements about longevity expectations (in wave 3 ) and have a negative influence on mortality between waves 3 and 4 . The consistent links among longevity expectations, health shocks, changes in activity limitations, and income persist through all three of the available mortality records.

However, longevity expectations do not capture all of the information some respondents may have about their health. Both smoking status and income in the preceding wave are significant determinants of mortality, after taking into account new health shocks and changes in activity restrictions. Column three of Table 1 reports a probit model with selection that drops these variables both from the mortality and the "alive in preceding wave" selection models. The link between longevity expectations and mortality appears somewhat stronger, with new health shocks and changes in activity restrictions remaining significant. Their coefficient estimates also have approximately the same magnitude as in the more detailed specification.

Column four of Table 1 examines a more limited record of the deaths between waves 2 and 3 and uses those individuals still alive by wave 2 in a selection equation. The last column provides the means for these variables based on this component of the panel. In this case, lagged values of health shock and activity changes were not available for the selection model. Their absence from the model does not alter the robust overall link between expectations and survival outcomes over time. Thus, our results indicate a consistent pattern relating longevity expectations to mortality throughout the full span of the panel currently available.

The second component of our findings stems from an inconsistency that seemed to arise from the longevity responses to waves 1 and 2 . Hurd and McGarry (1998) reported lower longevity expectations when they compared average re-
TABle 2-Temporal Evaluation of Longevity EXPECTATIONS FOR DIFFERENT SUBSAMPLES

\begin{tabular}{lccc}
\hline \hline & \multicolumn{3}{c}{ Live to 75 } \\
\cline { 2 - 4 } Respondent died before: & Wave 1 & Wave 2 & Wave 3 \\
\hline Wave 4 interviews & & & \\
$\quad$ Mean & 0.562 & 0.547 & 0.519 \\
$\quad$ Standard deviation & 0.343 & 0.311 & 0.387 \\
$\quad$ Number of observations & 231 & 202 & 154 \\
Wave 3 interviews & & & \\
$\quad$ Mean & 0.525 & 0.462 & \\
$\quad$ Standard deviation & 0.347 & 0.371 & \\
$\quad$ Number of observations & 211 & 167 & \\
Wave 2 interviews & & & \\
$\quad$ Mean & 0.445 & & \\
$\quad$ Standard deviation & 0.325 & & \\
$\quad$ Number of observations & 142 & & \\
\hline Respondent alive in: & Wave 1 & Wave 2 & Wave 3 \\
\hline Wave 4 interviews & & & \\
$\quad$ Mean & 0.652 & 0.640 & 0.654 \\
$\quad$ Standard deviation & 0.291 & 0.286 & 0.303 \\
Number of observations & 10,091 & 9,298 & 8,512 \\
\hline
\end{tabular}

sponses for wave 2 with those for wave 1 . One would have expected that those individuals surviving to a later wave would reassess the odds of living to age 75 as being higher, not lower. Table 2 reconsiders this issue by using a somewhat different perspective. The model hypothesizes a component in the longevity responses that reflects each individual's personalized knowledge of his or her own health condition, which may not be fully captured by using their reports about experienced health conditions. To investigate this issue, we considered respondents who died between waves 3 and 4 and those who survived to wave 4 as separate subsamples. The first row in Table 2 reports average values of longevity expectations of those individuals who died between waves 3 and 4 in each preceding interview. There is a clear downward trend, which suggests that these individuals may have had more information than could be used to estimate survival probabilities on an actuarial basis. Of course, the differences are small. Nonetheless, the pattern appears even more striking when we consider those individuals who survived to wave 4 (last row of Table $2)$. Their longevity expectations are significantly higher and do not decline over the full period. The second row of Table 2 repeats the evaluation for those individuals who died be- 
Table 3-Effect of Observed and Unobserved Conditions on Longevity Expectations over Time ${ }^{a}$

\begin{tabular}{|c|c|c|c|c|}
\hline \multirow[b]{2}{*}{ Independent variables } & \multicolumn{2}{|c|}{ Wave 3} & \multicolumn{2}{|c|}{ Wave 2} \\
\hline & Live to 75 & $\begin{array}{l}\text { Change in live to } 75 \\
\text { from wave } 2 \text { to } 3\end{array}$ & Live to 75 & $\begin{array}{l}\text { Change in live to } 75 \\
\text { from wave } 1 \text { to } 2\end{array}$ \\
\hline Live to 75 in wave $j-1$ & $\begin{array}{c}0.521 \\
(0.013)\end{array}$ & & $\begin{array}{c}0.498 \\
(0.010)\end{array}$ & \\
\hline $\begin{array}{l}\text { Health shock between } \\
\text { wave } j-1 \text { and } j\end{array}$ & $\begin{array}{c}-0.116 \dagger \\
(0.014)\end{array}$ & $\begin{array}{c}-0.051 \\
(0.015)\end{array}$ & $\begin{array}{c}-0.088 \\
(0.013)\end{array}$ & $\begin{array}{r}-0.038 \\
(0.015)\end{array}$ \\
\hline Smoke in wave $j$ & $\begin{array}{c}-0.043 \\
(0.008)\end{array}$ & $\begin{array}{r}-0.015 \dagger \\
(0.009)\end{array}$ & $\begin{array}{c}-0.027 \\
(0.006)\end{array}$ & $\begin{array}{c}-0.05 \times 10^{-2} \dagger \\
(0.007)\end{array}$ \\
\hline Death in wave $j+1$ & $\begin{array}{c}-0.031 \dagger \\
(0.031)\end{array}$ & $\begin{array}{r}-0.012 \dagger \\
(0.033)\end{array}$ & $\begin{array}{c}-0.102 \\
(0.025)\end{array}$ & $\begin{array}{c}-0.068 \\
(0.028)\end{array}$ \\
\hline Death in wave $j+2$ & & & $\begin{array}{r}-0.024 \dagger \\
(0.018)\end{array}$ & $\begin{array}{c}0.019 \dagger \\
(0.021)\end{array}$ \\
\hline Age in wave 1 & $\begin{array}{c}0.001 \dagger \\
(0.001)\end{array}$ & $\begin{array}{c}-0.03 \times 10^{-3} \dagger \\
(0.001)\end{array}$ & $\begin{array}{c}0.001 \\
(0.000)\end{array}$ & $\begin{array}{l}0.09 \times 10^{-2} \dagger \\
(0.001)\end{array}$ \\
\hline Mother alive $(=1)$ & $\begin{array}{c}0.022 \\
(0.007)\end{array}$ & $\begin{array}{l}0.03 \times 10^{-2} \dagger \\
(0.008)\end{array}$ & $\begin{array}{c}0.015 \\
(0.005)\end{array}$ & $\begin{array}{c}-0.004 \dagger \\
(0.006)\end{array}$ \\
\hline Father alive $(=1)$ & $\begin{array}{c}0.015 \dagger \\
(0.010)\end{array}$ & $\begin{array}{r}-0.004 \dagger \\
(0.011)\end{array}$ & $\begin{array}{r}0.006 \dagger \\
(0.006)\end{array}$ & $\begin{array}{c}0.009 \dagger \\
(0.007)\end{array}$ \\
\hline $\begin{array}{l}\text { Change in count of } \\
\text { activity limitations } \\
j-1 \text { to } j\end{array}$ & $\begin{array}{c}-0.027 \\
(0.004)\end{array}$ & $\begin{array}{c}-0.015 \\
(0.004)\end{array}$ & $\begin{array}{c}-0.024 \\
(0.005)\end{array}$ & $\begin{array}{r}-0.017 \\
(0.005)\end{array}$ \\
\hline Intercept & $\begin{array}{c}0.298 \\
(0.038)\end{array}$ & $\begin{array}{r}0.030 \dagger \\
(0.042)\end{array}$ & $\begin{array}{c}0.246 \\
(0.030)\end{array}$ & $\begin{array}{r}-0.054 \dagger \\
(0.033)\end{array}$ \\
\hline$R^{2}$ & 0.305 & 0.007 & 0.289 & 0.005 \\
\hline Sample size & 6,616 & 6,616 & 9,266 & 9,266 \\
\hline
\end{tabular}

a The numbers in parentheses are estimated standard errors. Unless marked $\dagger$ the estimated parameters are significantly different from zero with a $p$-value of at least 0.05 .

tween waves 2 and 3. The pattern is similar to their responses about longevity expectations in waves 1 and 2 . Thus, the evolution of subjective probabilities does appear to include an expectational component that may incorporate unobservable features of personal circumstances that bear on survival to age 75 .

The final aspect of our results seeks to test this question in more formal terms in Tables 3 and 4. Table 3 reports the simple Bayesian updating model frequently used to describe subjective probabilities (see W. Kip Viscusi and Charles J. O'Connor, 1984, or Smith et al., 1999 , as examples) for updates to longevity expectations between waves 1 and 2 and in waves 2 and 3 . In addition to measures of new information between waves 2 and 3-new health shocks and changes in the activity limitation variable that we described earlier-we include smoking status and, following the suggestions of Hamermesh (1985) and Hurd and McGarry (1998), the survival status of both parents. In general, the effects of parental vari- ables are consistent with the qualifications raised by these authors about how relatives' longevity experiences seem to be used by respondents in assessing their own longevity expectations.

Our primary purpose in considering this model was to test whether the longevity expectation measurement reflects all of the information known to an individual but not necessarily objectively observable at the time it was elicited. We tested this hypothesis by including the mortality status of respondents after they reported their longevity expectations.

To outline the structure of our test, consider a model specification that includes a qualitative variable indicating whether a respondent died during the two years after he reported his longevity expectations. Although respondents do not know they will die between this interview and the next (in two years' time), they may have information about their health status that is more complete than what is conveyed to the analyst by their reports about new health 
TABle 4-ReVERSE REgRession Test of LONGEVITy Expectations as a Sufficient Statistic ${ }^{\mathrm{a}}$

\begin{tabular}{|c|c|c|}
\hline Independent variable & Wave $j=3$ & Wave $j=2$ \\
\hline \multirow[t]{2}{*}{ Live to 75 (wave $j$ ) } & 0.875 & 0.876 \\
\hline & $(0.003)$ & $(0.003)$ \\
\hline \multirow[t]{2}{*}{ Mortality between waves $j$ and $j+1$} & 0.096 & 0.154 \\
\hline & $(0.027)$ & $(0.021)$ \\
\hline \multirow[t]{2}{*}{ Wald test ${ }^{\mathrm{b}}\left(\mathrm{Ho}: a_{2} / a_{1}=0\right)$} & 13.04 & 52.32 \\
\hline & $(0.000)$ & $(0.000)$ \\
\hline Sample size & 6,616 & 9,266 \\
\hline$R^{2}$ & 0.877 & 0.879 \\
\hline
\end{tabular}

${ }^{a}$ The numbers in parentheses indicate robust (Huber) standard errors in the first two rows. The third row reports the $F$ statistic for the Wald test and, in parentheses, the $p$-value for rejection of the null hypothesis. All estimated parameters are significantly different from zero, with $p$-values of at least 0.01 . The dependent variable is the predicted longevity expectations in wave $j$ based on the specification given in Table 3, excluding the qualitative variable for future mortality. Our conclusions do not change when this first round model is adjusted for selection effects relevant to each wave.

${ }^{\mathrm{b}}$ The Wald test for nonlinear hypothesis $R(\boldsymbol{\beta})=r$, with $R$ a function of the parametric vector $\boldsymbol{\beta}$, is $W=(R(\hat{\boldsymbol{\beta}})-r)^{T}\left[F V F^{T}\right]^{-1}(R(\hat{\boldsymbol{\beta}})-r)$, where $F$ is the derivative for $R(\boldsymbol{\beta})$ and $V$ is the estimate of the asymptotic covariance matrix for the estimated coefficients. The test was performed using Stata's TESTNL (STATA, 1999).

conditions and increases in activity restrictions. This strategy seems to offer a direct test. Unfortunately, it does not. Including a qualitative variable for future death in the longevity updating model simply reverses the causality implied, in our models, to test longevity expectations as a predictor of future mortality. Although one test is a probit (i.e., the mortality models in Table 1) and another is a regression (Table 3 ), this formulation of a test for unobservable factors only reverses the direction for "fitting" a prediction test. If both models were simple univariate regressions, they would yield the same results in large samples-consistent estimates of the effect of longevity expectations on mortality (Takeshi Amemiya, 1985 pp. 99-101).

A small change in the process yielded the test we wanted. It required fitting the model in two steps. First, we considered all of the observable information, including prior longevity beliefs, that would, with rational updating, contribute to longevity expectations in the wave after those events occurred. After fitting this equation with least squares, we could summarize the information implied by the updated model in the prediction for longevity expectations $\left(\hat{y}_{j}\right)$. This first step did not include the qualitative variable for future mortality. Following the logic of Delores A. Conway and Harry V. Roberts $(1983,1984)$ in testing for gender discrimination, we fitted a second-stage model regressing $\hat{y}_{j}$ on the actual longevity expectation, and a qualitative variable, $d_{j+1}$, for death between $j$ and $j+1$, as in equation (1). The specification in equation (1) restricts the relationship from passing through the origin because an intercept is included in the equation used to predict longevity expectations. ${ }^{7}$

$$
\hat{y}_{j}=a_{1} y_{j}+a_{2} d_{j+1}+\varepsilon_{j} .
$$

As Arthur S. Goldberger (1984) explained in commenting on this proposal for tests of discrimination, this reverse regression test adopts the null hypothesis that all factors determining longevity expectations are fully reflected in $\hat{y}_{j}$. The only other influence consistent with the test is a random

\footnotetext{
${ }^{7}$ The sign of the estimated parameter for $d_{j+1}$ is affected by this restriction. This arises because a restriction on the intercept affects the interpretation of $a_{2}$. We would like to interpret our estimate of $a_{2}$, when normalized by $a_{1}$ (i.e., $\left.-a_{2} / a_{1}\right)$, as a test of the sufficiency of $\hat{y}_{j}$ in predicting $y_{j}$. If the model estimating $\hat{y}_{j}$ reflects all respondents' information, then these individuals' reports in $j$ cannot be influenced by a death in $j+1$. A model with an intercept in equation (1) has the effect reflected both in $-a_{0} / a_{1}$ (with $a_{0}$ being the intercept) and $-a_{2} / a_{1}$. This specification would preclude a simple interpretation of the effect of the future-death term.
} 
error $\left(\varepsilon_{j}\right)$ uncorrelated with mortality. Any other influences on "true" longevity expectations (unknown to the analyst) must have the same means for those who die and those who survive. Under these conditions, a test where $\left(-a_{2} / a_{1}\right)$ is different from zero gauges whether longevity expectations provide a sufficient statistic, incorporating all that respondents know about their subjective beliefs about survival.

This framework does not simply reverse the prediction test. Table 4 reports our tests for waves 2 and 3. In contrast to the results of the simple tests in Table 3, the significant negative estimates for $\left(-a_{2} / a_{1}\right)$, using a Wald test, imply that we must reject the hypothesis that an individual's longevity expectation contains all of the information that each person knows about his or her survival prospects. Moreover, they are consistent with the temporal patterns described in Table 2. That is, the reverse regression framework allows a comparison of estimates for longevity expectations, assuming they arise from the Bayesian updating framework. Our test implies that all respondents with comparable reported longevity expectations, whether they survive to a future wave or not, should have the same estimates for longevity expectations, based on the updating model. The negative and significant estimate for the parameter $\left(-a_{2} / a_{1}\right)$ that is associated with the variable indicating whether a respondent dies after reporting a longevity expectation, implies that these respondents would report lower survival prospects than those that the model based on their responses would estimate for them. These results hold for waves 2 and 3. Thus, respondents who later die appear to have information (in addition to their reported health shocks and activity limitations) that is relevant to their perceived survival prospects but is not reflected in the updating models that describe how new information affects these expectations. Thus, we conclude that although our models of longevity expectations are generally consistent with the micro outcomes, they do not incorporate all of the factors that a person expects to be relevant for survival to age 75 or older.

\section{Implications}

Until now, it has been largely impossible to evaluate how subjective perceptions of mortal- ity fare as predictions of death at the individual level. The HRS has changed the landscape for evaluations of risk perceptions. Our analysis took the most complete version of the HRS available and evaluated the relationship between subjective beliefs about mortality and actual deaths at the individual level. We found remarkable, but not complete, consistency.

These longevity expectations are reasonably good predictions of future mortality. They are also consistently updated with new health information but do not appear to reflect all of the information that respondents who subsequently die know about their survival prospects. In short, their reported longevity expectations are lower than the updating model would imply for them after taking into account new health shocks and activity restrictions. The estimated effect is relatively small, -0.11 , but significantly estimated for both sets of comparisons (i.e., waves 3-4 and 2-3). Those individuals who later die appear to know more about their health status than is reported in their ratings of activity limitations and new health shocks. As a result, this future death is negatively associated with their answers to the longevity questions elicited at an earlier date. Nonetheless, our findings leave little room for doubt about whether these subjective perceptions of longevity should be taken seriously. It is clear that they should. Subjective risk perceptions have important implications for models of savings behavior, life cycle decisions, labor supply and retirement, and the development of information programs about risky behaviors (e.g., smoking, substance abuse, etc.). The next step in the research process would seem to be to develop models of economic behavior that accept measures of subjective risk perceptions as legitimate and then investigate their relative importance, in comparison to more conventional economic variables, in explaining how people's behavior responds to these expectations being updated with new information.

\section{REFERENCES}

Amemiya, Takeshi. Advanced econometrics. Cambridge, MA: Harvard University Press, 1985.

Conway, Delores A. and Roberts, Harry V. "Reverse Regression, Fairness and Employment 
Discrimination." Journal of Business and Economic Statistics, January 1983, 1(1), pp. 75-85.

- "Rejoinder to Comments on 'Reverse Regression, Fairness, and Employment Discrimination'." Journal of Business and Economic Statistics, April 1984, 2(2), pp. 12639.

Fischhoff, Baruch; Postrom, A. and Quadrel, M. J. "Risk Perception and Communication." Annual Review of Public Health, 1993, 14(1), pp. 183-203.

Goldberger, Arthur S. "Redirecting Reverse Regression." Journal of Business and Economic Statistics, April 1984, 2(2), pp. 114-16.

Hamermesh, Daniel S. "Expectations, Life Expectancy, and Economic Behavior." Quarterly Journal of Economics, May 1985, 100(2), pp. 389-408.

Heckman, James J. "Sample Selection Bias as Specification Error." Econometrica, January 1979, 50(1), pp. 153-62.

Hurd, Michael D.; McFadden, Daniel and Merrill, Angela. "Predictions of Mortality Among the Elderly." National Bureau of Economic Research (Cambridge, MA), Working Paper No. W7440, December 1999.

Hurd, Michael D. and McGarry, Kathleen. "The Predictive Validity of Subjective Probabilities of Survival." Unpublished manuscript, Rand Corporation, June 1998.

Juster, F. Thomas and Suzman, Richard. "An Overview of the Health and Retirement Study." Journal of Human Resources, 1995; (Supp.), 30, pp. S7-S56.

Machina, Mark J. "Choices Under Uncertainty:
Problems Solved and Unsolved," in P. B. Hammond and R. Coppock, eds., Valuing health risks, costs, and benefits for environmental decision making. Washington, DC: National Academy Press, 1990, pp. 134-88.

Smith, V. Kerry; Desvousges, William H.; Fisher, Ann and Johnson, F. Reed. "Communicating Radon Risk Effectively: A Mid-Course Evaluation." Report to U.S. Environmental Protection Agency, EPA-230-07-87-029, July 1987.

Smith, V. Kerry; Taylor, Donald H., Jr.; Sloan, Frank A.; Johnson, F. Reed and Desvousges, William H. "Do Smokers Respond to Health Shocks?" Unpublished manuscript, Center for Health Policy, Law and Management, Duke University, February 1999.

STATA. STATA Reference Guide, Release 6. College Station, TX: Stata Press, 1999.

U.S. Department of Commerce. Statistical $a b$ stract of the United States. Washington, DC: U.S. Government Printing Office, 1999.

van de Ven, Wynand P. M. M. and van Praag, Bernard M. S. "The Demand for Deductibles in Private Health Insurance: A Probit Model with Sample Selection." Journal of Econometrics, November 1981, 17(2), pp. 229-52.

Viscusi, W. Kip and O'Connor, Charles J. “Adaptive Responses to Chemical Labeling: Are Workers Bayesian Decision Makers?" American Economic Review, December 1984, 74(5), pp. 942-56.

White, Halbert. "Maximum Likelihood Estimation of Misspecified Models." Econometrica, January 1982, 50(1), pp. 1-25. 